\title{
Gradual increase in self-stimulation response rates: Effect of electrode loci
}

\author{
DAVID C. DOUGLIN and ROBERT B. GLASSMAN \\ Lake Forest College, Lake Forest, Illinois 60045
}

\begin{abstract}
Nine male rats, each with electrodes implanted in a telencephalic region and seven of them also with successful placements in a more caudal brain reward region, were taught to selfstimulate. Rates in the caudate nucleus and medial frontal cortex showed a gradual increase over daily sessions, but self-stimulation in lateral hypothalamus, substantia nigra, and reticular formation did not have this property. In the telencephalon, rates in the first five testing sessions were low, averaging 138 barpresses/10-min session. ICSS rates gradually rose during approximately the next 15 sessions, leveling off at an average of $453 / 10 \mathrm{~min}$. Seizures were sometimes observed as rates increased at telencephalic points. Cumulative recordings showed that the long-term overall increase in response rate was partly due to a rate increase that occurred within some individual sessions, although during the last test days, a fast, steady rate dominated the entire session. The possibilities are discussed that the plasticity in ICSS is related to the kindling phenomenon or to dyskinesias which result from chronic administration of drugs presumed to have their main locus of action in the corpus striatum.
\end{abstract}

In taking intracranial self-stimulation (ICSS) measurements from two rats preparatory to pharmacological manipulations, it appeared that there was a systematic change over daily sessions in ICSS rate at telencephalic points (caudate nucleus and medial frontal cortex) but not at more caudal points. It would be interesting to know whether there is some special plasticity of the telencephalon, measurable by ICSS rates. In addition to its possible relevance to other neuroplasticity phenomena, such as kindling (Gaito, 1976) and its relevance to the broad question of the neural substrates of learning, knowledge of a special changeability of the caudate nucleus might help in understanding the origins of dyskinesias that arise spontaneously or that result from chronic drug treatments (Yahr, 1976). Therefore, we replicated the early results in additional animals, some of which had electrodes implanted both at the telencephalic loci and also at more caudal points, i.e., lateral hypothalamus, substantia nigra, or midbrain reticular formation.

\section{METHOD}

\section{Subjects}

Nine mature male albino rats, obtained from Holtzman Laboratories and weighing an average of $488 \mathrm{~g}$ at the time of surgery, were used. The rats were individually housed in wire-mesh cages, $24.5 \times 18 \times 17 \mathrm{~cm}$ high, with food and water always available.

\section{Surgery}

Rats were anesthetized with Nembutal and placed in a stereotaxic instrument with the incisor bar $5 \mathrm{~mm}$ above the interaural

Supported by a grant from the State of Illinois Department of Mental Health and Developmental Disabilities. Reprint requests may be sent to the second author. line. Monopolar stainless steel electrodes, made from full hard temper orthodontic wire, were used. The electrodes were $.25 \mathrm{~mm}$ in diameter and were insulated with Epoxylite varnish except for a conical, sharpened tip, .5-.8 mm long. All nine rats had electrodes implanted in the telencephalon. No animals had to be discarded because of lack of telencephalic self-stimulation. One other animal died following surgery. All animals also had more caudal placements, but only seven of the nine were found to be at points whose stimulation was rewarding. Placements, verified histologically, are indicated in Figure 1 . In all cases, a bare stainless steel wire, $2 \mathrm{~cm}$ long, was implanted under the scalp, to the side of the electrode rig. This relatively large conducting surface was used as the indifferent electrode for stimulation. No evidence was seen in any animal of sensory effects arising from the current at the indifferent electrode.
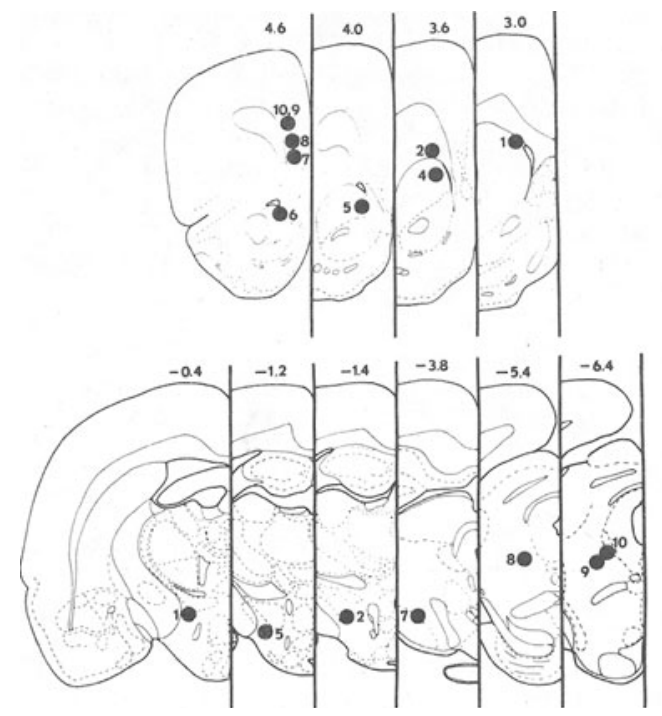

Figure 1. Electrode placements at telencephalic points (top row of sections) and at the more caudal points (bottom row). Sections from the atlas of Pellegrino and Cushman. 


\begin{abstract}
Apparatus
Rats were tested in a Skinner box, $30 \times 22 \times 39 \mathrm{~cm}$ high, placed inside a soundproof booth. A Grass S6 stimulator was used as the source of monophasic negative pulses, .1 msec duration, delivered to the monopolar brain electrode at a rate of $100 / \mathrm{sec}$, with a train duration of $.2 \mathrm{sec}$. To help hold current levels constant, the animal was placed in series with a $38-\mathrm{K}$ resistor. Current was monitored on an oscilloscope by measuring the voltage drop across an additional, 10-ohm series resistor. Barpresses were recorded on an automatic counter and also, during most sessions, with a cumulative recorder.
\end{abstract}

\section{Procedure}

One week after surgery, the animals were tested for ICSS in the telencephalon and other brain regions. After testing for ICSS, during the first seven sessions with the first two animals (Rats 1 and 2) and using varied current intensities that were lower than those finally used, intensities were selected which produced a reliable, low ICSS rate. The data from these first days in the two rats are not included in the data presented below. Recordings were initiated with the remaining seven animals without trying varied intensities. Our initial reason for selecting intensities that produced low rates of ICSS was to allow for seeing an increase that might result from pharmacological manipulations. Two current intensities were arbitrarily assigned to telencephalic points: $.74 \mathrm{~mA}$ (Rats $1,2,9,10$ ) or $.55 \mathrm{~mA}$ (Rats $4,5,6,7,8$ ). The more caudal regions were stimulated with intensities of $.2 \mathrm{~mA}$ (Rats $1,7,8,9,10$ ) or .45 mA (Rats 2,5 ). Intensities used in telencephalic regions did not elicit forced motor responses, but the higher intensities used at the telencephalic points did have such an effect when they were briefly tried in most rats at the more caudal points. Although somewhat higher intensities than those finally settled upon could have been used without causing motor problems at the more caudal electrodes, it was also desired to keep the response rate low at these points in order to allow for increases resulting from other factors.

Animals which demonstrated ICSS at both a telencephalic site and at a more caudal site were tested at both sites in each daily session. The test routine was as follows: After the animal was connected and placed in the test box, 2 min were allowed before beginning the 10-min session during which data were recorded. In the seven animals which were tested at two points, the first point was disconnected after the first 10-min interval and the second point was immediately connected. The second 10-min interval of recording ICSS rate data was then begun a total of 5 min after the end of the first 10 -min interval. Rats 1 and 2 were tested first at their more caudal electrodes while the other seven rats were tested first at their telencephalic points. The same order was used every day for a given rat.

During only 1 of the first 6 days of ICSS, the testing session for the telencephalic electrode was extended to $20 \mathrm{~min}$ with each of five rats. The rats were tested 7 days a week, except for a single occasion on which five rats were not tested during a break of 4 consecutive days. Testing was continued until a stable rate was achieved. This was defined as having occurred when 8 of 10 consecutive daily telencephalic ICSS rates fell within $20 \%$ of the average of the 10 rates.

\section{Histology}

The animals used in this study were subsequently used for 4 months in a study involving chronic haloperidol administration. Upon completion of that study, the rats were given an overdose of Nembutal and then perfused through the heart with saline and then with $10 \%$ Formalin. Rigs containing electrodes were removed ' carefully from the skull, and the brain was dehydrated and embedded in celloidin. Selected $40-\mu$ sections were stained in cresyl violet and mounted on slides.

\section{RESULTS}

An overall increase in ICSS over successive sessions was observed in the telencephalon but not in the other brain regions. Table 1 gives the average number of responses per 10-min session, at each point, for the first five and last five sessions, for each rat. The table also indicates the total number of sessions run, dependent on the time taken to reach the criterion of stability. Telencephalic sites showed increases, with the final rates, of as much as nine times the initial rates. Lower brain regions showed increases or decreases in different cases, with increases not being nearly as great as that found in the telencephalon. Whether the telencephalic site was tested first or second did not appear to make a difference; Rats 1 and 2 , in which the telencephalon was tested second, showed increases of about the same magnitude as the other animals.

Another interesting characteristic of responsiveness in the telencephalic region was the prominent increase in rate seen in the cumulative records of some individual sessions. The period during which this was seen varied from rat to rat, but generally it occurred after the first 3 test days and was no longer seen during the final, asymptotic 10 test days. These rate changes within a session were clear because the response rate within each session was very regular for telencephalic points, while it was much more irregular at the other points, with the stimulus intensities used. Figure 2 illustrates all of these observations about within-session rates.

On each of the single occasions in which a telencephalic self-stimulation session was extended to 20 min during the early days of testing, an increased rate was observed during the latter $10 \mathrm{~min}$. The individual data comparing barpresses in the first $10 \mathrm{~min}$ to the second 10 min for Rats $1,2,4,5$, and 6, re-

Table 1

Early and Late Response Rates for ICSS at Telencephalic Points and at More Caudal Points

\begin{tabular}{|c|c|c|c|c|c|c|c|c|c|c|}
\hline & & \multicolumn{9}{|c|}{ Rat } \\
\hline & & 1 & 2 & 4 & 5 & 6 & 7 & 8 & 9 & 10 \\
\hline $\begin{array}{l}\text { Telencephalic } \\
\text { ICSS Rate }\end{array}$ & $\begin{array}{l}\text { First Five Sessions } \\
\text { Last Five Sessions }\end{array}$ & $\begin{array}{r}94 \\
624\end{array}$ & $\begin{array}{r}52 \\
475\end{array}$ & $\begin{array}{r}81 \\
519\end{array}$ & $\begin{array}{l}111 \\
312\end{array}$ & $\begin{array}{l}148 \\
540\end{array}$ & $\begin{array}{r}84 \\
213\end{array}$ & $\begin{array}{l}225 \\
503\end{array}$ & $\begin{array}{r}74 \\
498\end{array}$ & $\begin{array}{l}324 \\
394\end{array}$ \\
\hline $\begin{array}{l}\text { Caudal Point } \\
\text { ICSS Rate }\end{array}$ & $\begin{array}{l}\text { First Five Sessions } \\
\text { Last Five Sessions }\end{array}$ & $\begin{array}{l}512 \\
744\end{array}$ & $\begin{array}{l}706 \\
444\end{array}$ & & $\begin{array}{l}523 \\
419\end{array}$ & & $\begin{array}{l}210 \\
233\end{array}$ & $\begin{array}{l}332 \\
351\end{array}$ & $\begin{array}{r}265 \\
0\end{array}$ & $\begin{array}{l}499 \\
224\end{array}$ \\
\hline \multicolumn{2}{|c|}{ Total Number of Sessions } & 30 & 33 & 33 & 43 & 30 & 45 & 26 & 24 & 26 \\
\hline
\end{tabular}




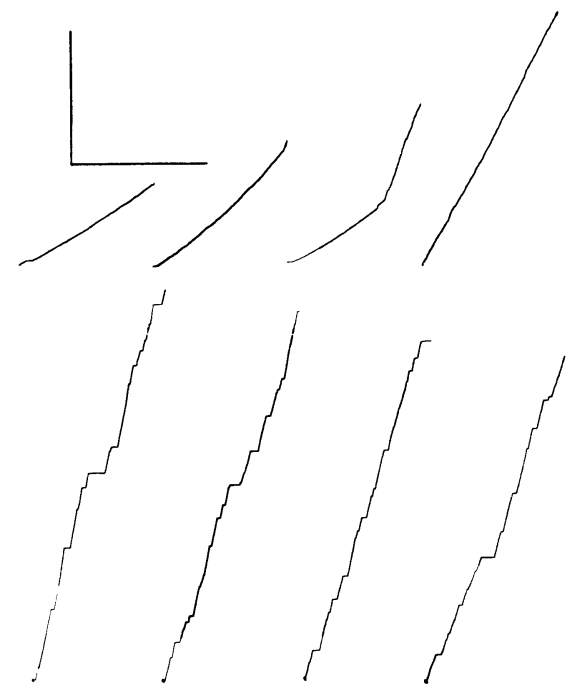

Figure 2. Cumulative recordings from Rat 5 for ICSS in caudate nucleus (top row) and lateral hypothalamus (bottom row) on Days 1, 8, 10, and 27. Calibration: 200 barpresses, $10 \mathrm{~min}$.

spectively, are as follows: $80 / 186,103 / 242,64 / 144$, $83 / 175$, and $155 / 690$. It should be recalled that these data were obtained even though the scores for the first 10 min do not include the 2-min "warm-up" periods.

During the first few test days, Rats 4 and 7 exhibited shaking behavior, or "chills," following almost every barpress for ICSS at telencephalic points. Other rats only occasionally exhibited shaking behavior between presses, but assumed a still posture or groomed briefly, during this early phase of slow, regular barpressing. Behavioral seizures occurred occasionally in all rats. Following telencephalic selfstimulation, the rats were often hypersensitive and difficult to handle.

\section{DISCUSSION}

Plasticity is not generally thought to be a characteristic of self-stimulation behavior. Olds (1977, p. 19) attributed increased ICSS response rate, seen in some cases during the first few weeks, to time since surgery rather than to any growing "addiction." Cooper and Taylor (1967) reported gradual increase in ICSS at points in periventricular gray over the first few sessions. Enhancement, to the extent of seizures, in responsiveness to electrical or cholinergic stimulation of telencephalic points, including caudate nucleus, is an outcome of studies of "kindling" (Gaito, 1976; Vosu \& Wise, 1975). Telencephalic points appear particularly susceptible to epileptic activity during self-stimulation experiments (Routtenberg \& Santos-Anderson, 1977). Campbell, Milgram, and Christhoff (1976) concluded that kindling enhanced the reward value of hippocampal ICSS. Animals of the present experiment showed progressive increases in the rate of self-stimulation, during daily 10-min sessions, at points in caudate nucleus and nearby medial frontal cortex. Such changes were not seen at more caudal points (lateral hypothalamus, substantia nigra, midbrain reticular formation) in the same animals, although conditions were arranged so that the ICSS rates obtained at these points were in the same general range as those obtained from the telencephalic points. The phenomenon observed in this experiment resembles the "priming" effect (Deutsch, 1973, pp. 504-550), except that the present effect has a much longer time course.

It should be noted that even though a lower level of current was used at the caudal points, the initial rate of self-stimulation here was higher than at the telencephalic points. Preliminary observations suggested that using still less current caudally would have yielded an irregular, unreliable response rate, while current as high as that used in the telencephalon elicited forced motor responses. The telencephalic current settings were as low as they could be to obtain reliable ICSS. Thus, in view of the initial differences in responsiveness of the telencephalon, as compared to the caudal points, the current settings were as comparable as we could make them. Although telencephalic rates were initially less than caudal rates in all cases, the final telencephalic rates actually surpassed the caudal rates in three rats (Nos. 8, 9, 10) and converged strongly in the others. This suggests that the current settings were appropriately selected.

EEG observations, subsequent to the behavioral observations reported here, suggested that the ICSS rate increase at telencephalic points might be a function of increased local excitability, manifest as electrographic seizure activity. The ICSS rate increase might therefore be a result of kindling. Some observations suggest that this effect is at least partly reversible; in four of five cases, telencephalic response rates decreased, by about $100-250$ responses/10-min session, after a 4-day break. Moreover, in another study (in preparation), most of these rats showed a decrease in ICSS rate following withdrawal from haloperidol.

The present results suggest a special plasticity of telencephalic self-stimulation as a function of stimulation experience. Manipulation of current intensity is another independent variable that affects telencephalic points differentially; ICSS rate in the lateral hypothalamus and substantia nigra increased appropriately in response to current intensity increments of $25 \%, 50 \%$, and $75 \%$ above baseline intensity, while ICSS rates in the medial frontal cortex showed no such increases (Goodall \& Carey, 1975). Thus, in contrast to the present results, manipulation of this independent variable actually suggests less plasticity of telencephalic responsiveness. 
In general, three phases of telencephalic ICSS can be identified. During the first few days, there is usually a slow, regular rate throughout the entire session. Next, increases in rate occur during sessions. Finally, a consistent, fast, regular daily rate is seen. Recordings taken during the single, extended 20-min session suggested that even during the first test days rate increments would have occurred if longer sessions had been run. These observations suggest some sort of cumulation of excitation that occurs from day to day and also within individual sessions.

Indirect evidence for a special plasticity of the basal ganglia, resulting from chronic stimulation, comes from pharmacological studies. A variety of evidence indicates that both dopamine and agents that antagonize dopamine have their main site of action in the corpus striatum (Snyder, Banerjee, Yamamura, \& Greenberg, 1974). Ellinwood and Kilbey (1975) have reported that chronic administration of amphetamine, a catecholaminergic agonist, leads to learning idiosyncratic movement stereotypies. However, it is also true that the catecholamines act as neurotransmitters elsewhere and that electrical self-stimulation at points in the brain other than the corpus striatum involves catecholaminergic transmission (Olds, 1977).

Interestingly, a long-term antagonism of catecholamines also leads to what might be considered a form of "learning." Psychotic patients who have been maintained on neuroleptic drugs for intervals of months to years often develop a syndrome of abnormal mouth movements called tardive dyskinesia. Similar results have been obtained in animals (Smith \& Davis, 1975; Glassman, Glassman, \& Frew, 1977). Klawans (1973) has suggested that tardive dyskinesia may be accounted for by a dopaminergic denervation hypersensitivity, or else by a kindling effect, in the corpus striatum. While this idea is consistent with the interpretation of our results offered here, research underway has not yet shown electrographic evidence of enhanced seizure activity in basal ganglia or frontal cortex resulting from long-term administration of haloperidol or chlorpromazine (Douglin \& Glassman, 1978; Glassman et al., 1977).

The pharmacological evidence cited above in reference to the striatum may also be relevant to the frontal cortex, with which the caudate nucleus is connected (Divac, 1972). As shown in Figure 1, the medial frontal cortex points yielding self-stimulation in the present experiment and in earlier research (Routtenberg \& Santos-Anderson, 1977) are very close to the points in caudate nucleus. It is difficult to say whether we obtained similar results from these two areas because of spread of current, passing fibers (Routtenberg \& Santos-Anderson, 1977), or functional connections. Research is currently in progress to see whether telencephalic self-stimulation is permanently modified after withdrawal from neuroleptics.

\section{REFERENCES}

Campbell, K. A., Milgram, N. W., \& Christhoff, J. K. Development of hippocampal reward through repeated daily electrical stimulation (kindling). Society for Neuroscience $A b$ stracts, 1976, 2, 381.

CoOper, R. M., \& TAYlor, L. H. Thalamic reticular system and central grey; self stimulation. Science, 1967, 156, 102-103.

Deutsch, J. A. Physiological psychology (rev. ed.). Homewood, Ill: Dorsey, 1973.

Divac, I. Neostriatum and functions of prefrontal cortex. Acta Neurobiologiae Experimentalis, 1972, 32, 461-477.

Douglin, D. C., \& Glassman, R. B. Changes in telencephalic self-stimulation rate resulting from prior self-stimulation experience and from chronic haloperidol. Society for Neuroscience Abstracts, 1978, 4, 490.

Ellinwood, E. H., \& Kilbey, M. M. Amphetamine stereotypy: The influence of environmental factors and prepotent behavioral patterns on its topography and development. Biological Psychiatry, 1975, 10, 3-16.

GaITo, J. The kindling effect as a model of epilepsy. Psychological Bulletin, 1976, 83, 1097-1109.

Glassman, R. B., Glassman, H. N., \& Frew, C. Possible feline analog of tardive dyskinesia. Society for Neuroscience Abstracts, $1977,3,441$.

Goodall, E. B., \& CAREY, R. J. Effects of d- versus l-amphetamine, food deprivation, and current intensity on self-stimulation of the lateral hypothalamus, substantia nigra, and medial frontal cortex of the rat. Journal of Comparative and Physiological Psychology, 1975, 89, 1029-1045.

KLawans, H. L. The pharmacology of tardive dyskinesias. American Journal of Psychiatry, 1973, 130, 82-86.

Ouds, J. Drives and reinforcements: Behavioral studies of hypothalamic functions. New York: Raven, 1977.

Routtenberg, A., \& Santos-Anderson, R. The role of prefrontal cortex in intracranial self-stimulation: A case history of anatomical localization of motivational substrates. In L. L. Iversen, S. D. Iversen, \& S. H. Snyder (Eds.), Handbook of psychopharmacology (Vol. 8) Drugs, neurotransmitters, and behavior. New York: Plenum, 1977.

Smith, R. C., \& DAvis, J. M. Behavioral supersensitivity to apomorphine and amphetamine after chronic high does haloperidol treatment. Psychopharmacology Communications, 1975, 1, 285-293.

Snyder, S. H., Banerjee, S. P., Yamamura, H. I., \& Greenberg, D. Drugs, Neurotransmitters, and schizophrenia. Science, 1974, 184, 1243-1253.

Vosu, H., \& Wise, R. A. Cholinergic seizure kindling in the rat: Comparison of caudate, amygdala and hippocampus. Behavioral Biology, 1975, 13, 491-495.

YAHR, M. D. (Ed.) The basal ganglia. New York: Raven, 1976.

(Received for publication September 19, 1978; revision accepted March 28, 1979.) 